\title{
Evaluation of Transcervical Insemination using Frozen Semen by Flexible Endoscope in Dogs
}

\author{
Kohtaro HAYASHI ${ }^{1)}$, Risa MORITA ${ }^{2)}$, Takuya ASO ${ }^{2)}$, Mamiko ONO ${ }^{2)}$, Tadatoshi OHTAKI ${ }^{2)}$, Koichi TANEMURA ${ }^{2)}$, \\ Toshihiro WATARI ${ }^{1)}$ and Shigehisa TSUMAGARI ${ }^{2) *}$ \\ ${ }^{1)}$ Laboratory of Comprehensive Veterinary Studies, College of Bioresource Sciences, Nihon University, 1866 Kameino, Fujisawa, \\ Kanagawa 252-0880, Japan \\ 2) Laboratory of Theriogenology, College of Bioresource Sciences, Nihon University, 1866 Kameino, Fujisawa, Kanagawa 252-0880, \\ Japan
}

(Received 13 June 2012/Accepted 17 October 2012/Published online in J-STAGE 31 October 2012)

ABSTRACT. We evaluated transcervical insemination (TCI) using frozen semen by flexible endoscopy in dogs. Eight female and eight male beagles were used in this study. A flexible endoscope and a washing tube were used for TCI. A tracheal tube was used as an alternative to the penis and was an auxiliary for inserting the flexible endoscope. The mean time required to insert the washing tube into the external os of the uterus after inserting the endoscope into the tracheal tube was $7.5 \mathrm{~min}$. Slight or mild pain was observed in all bitches during TCI. However, TCI could be easily performed with retention in all bitches and without sedation anesthesia. The tracheal tube was useful to ensure the visual field using air sufflation. Clinical signs suspicious of infection were not observed in any bitches from the TCI to the pregnancy diagnosis. The conception rate was $87.5 \%$, and the mean number of fetuses was 6.3 . TCI using a flexible endoscope in bitches was performed quickly with minimal invasiveness. We present a new method of TCI in dogs. This method should be studied in small and large breeds to obtain more detailed results.

KEY WORDS: canine, flexible endoscope, frozen semen, transcervical insemination.

doi: 10.1292/jvms.12-0273; J. Vet. Med. Sci. 75(3): 315-318, 2013

Artificial insemination (AI) using frozen semen in dogs has been increasing in recent years. However, AI using cryopreserved semen generally yields lower pregnancy rates with vaginal deposition than with uterine deposition because of the short life span of frozen-thawed spermatozoa [5, 19]. Therefore, AI methods usually use uterine deposition with frozen semen. Surgical insemination is highly invasive and requires general anesthesia, whereas transcervical insemination (TCI) using metal catheterization is minimally invasive but requires a skilled technique [24]. In contrast, TCI using a rigid endoscope is easy and less invasive $[13,30]$. TCI with a flexible endoscope is also less invasive because the scope is soft, and it has an air supply and instrument channel, which endows it with good operability [21, 29]. Therefore, a flexible endoscope might be useful as a new tool for TCI.

The purpose of this study was to evaluate TCI using frozen semen by flexible endoscope in dogs.

\section{MATERIALS AND METHODS}

Eight female beagles aged 1-8 years (mean \pm standard deviation: SD, $4.1 \pm 2.5$ years) and weighing 10.7-15.1 $\mathrm{kg}$ (mean $\pm \mathrm{SD}, 12.8 \pm 1.3 \mathrm{~kg}$ ) were used in this study; 4 were parous, and the others were nulliparous. Eight male beagles aged $1-7$ years (mean $\pm \mathrm{SD}, 3.6 \pm 1.8$ years) and

*Correspondence to: Tsumagari, S., Laboratory of Theriogenology, College of Bioresource Sciences, Nihon University, 1866 Kameino, Fujisawa, Kanagawa 252-0880, Japan.

e-mail: tsumagar@brs.nihon-u.ac.jp

(C)2013 The Japanese Society of Veterinary Science weighing 11.4-15.8 $\mathrm{kg}$ (mean $\pm \mathrm{SD}, 13.1 \pm 1.4 \mathrm{~kg}$ ) were used as sperm donors. Unrelated dogs were used to prevent inbreeding. This study was performed in accordance with the Guide for the Experimentation of Animals of the College of Bioresource Sciences, Nihon University (AP11B018, 2010).

The sperm-rich fraction of a single ejaculate was collected from each dog by digital manipulation [11]. The collected semen was centrifuged at $400 \times \mathrm{g}$ for $5 \mathrm{~min}$. The supernatant was discarded, and the pellets were gently suspended in $1 \mathrm{~m} l$ with egg-yolk Tris-fructose citrate extender supplemented with $1 \%$ Orvus ES paste (OEP) [26-28]. Sperm concentration was measured 3 times in each sample with an automated blood cell counter (MEK-5257, Nihon Koden, Tokyo, Japan), and the average value was used. Finally, the prepared semen was adjusted to $200 \times 10^{6} \mathrm{sperm} / \mathrm{m} l$ in a glass vial with the same extender. The adjusted semen was cooled from $25^{\circ} \mathrm{C}$ to $4^{\circ} \mathrm{C}$ for 60 min using a programmed freezer (ET-1N type, Fujihira Industry, Tokyo, Japan). The semen was subsequently diluted to $100 \times 10^{6} \mathrm{sperm} / \mathrm{m} l$ with egg-yolk Tris-fructose citrate extender supplemented with $1 \%$ OEP and $10 \%$ glycerol in the programmed freezer, and a glycerol equilibration was performed for $60 \mathrm{~min}$ at $4{ }^{\circ} \mathrm{C}$. The final concentrations of OEP and glycerol were $0.5 \%$ and $5 \%$, respectively. After equilibration, the semen was packed into $0.5-\mathrm{m} l$ straws. The semen straws were horizontally placed on a $7-\mathrm{cm}$ high stainless steel rack from the surface of the liquid nitrogen in a styrene foam box $(27.5 \times 23.4 \times 14.0 \mathrm{~cm}$ and $1.8 \mathrm{~cm}$ thick) for $10 \mathrm{~min}$ and stored in a liquid nitrogen tank $[17,18,20]$. Frozen semen was thawed by immersing the straws in a water bath at $70^{\circ} \mathrm{C}$ for $8 \mathrm{sec}$ just before AI [16]. Sperm progressive motility and sperm malformation 
rate were evaluated by direct microscopic examination.

The timing of insemination in relation to the luteinizing hormone $(\mathrm{LH})$ surge was determined by monitoring serum progesterone $\left(\mathrm{P}_{4}\right)$ concentration using an automated chemiluminescence immuno analyzer (Spotchem Vidas SV-5020, Arkray, Kyoto, Japan) [1, 2, 4, 7, 8, 14]. The start date of proestrus was confirmed by daily observation of vulvar swelling and estrous bleeding. Serum $\mathrm{P}_{4}$ concentrations were measured daily after 5 days from confirming the beginning of proestrus or the appearance of $>80 \%$ cornified cells in the vaginal smear. In principle, the estimated day of the $\mathrm{LH}$ surge was determined when serum $\mathrm{P}_{4}$ concentrations first reached 2-4 $n \mathrm{~g} / \mathrm{ml}$. However, among bitches in which serum $\mathrm{P}_{4}$ concentration was initially $<2 \mathrm{ng} / \mathrm{ml}$ and then rapidly increased to $>4 \mathrm{ng} / \mathrm{m} l$ the next day, the estimated day of the LH surge was determined when the serum $\mathrm{P}_{4}$ concentration was $>4 n \mathrm{~g} / \mathrm{ml}$. The serum $\mathrm{P}_{4}$ concentration was measured on the fifth day after the LH surge day (day 0) when the TCI was performed.

The bitch was retained in the prone position on an operating table that was angled at about 30 degrees so that the tail was high and the head was low. A flexible endoscope (VQ-6092-A: outside diameter, $6 \mathrm{~mm}$; Olympus, Tokyo, Japan) was used for TCI. A tracheal tube (inside diameter: $10.0 \mathrm{~mm}$, outside diameter: $13.7 \mathrm{~mm}$, Portex, Smiths Medical, St. Paul, MN, U.S.A.) was inserted into the vulva as a guide tube for the flexible endoscope. Then, the tracheal tube cuff was injected with air to prevent inflow of air into the bladder. The cuff air volume in the tracheal tube (30-45 $\mathrm{m} l$ ) was adjusted according to the physique of the bitch. The flexible endoscope was inserted into the tracheal tube, and the position of the external os of the uterus was confirmed (Fig. 1). A washing tube for bronchial lavage (PW-2L1: outside diameter, $1.8 \mathrm{~mm}$; Olympus) filled with egg-yolk
Tris-fructose citrate was inserted into the external os of the uterus from the channel in the endoscope, and $1 \mathrm{ml}(100 \times$ $10^{6}$ sperm) of thawed semen was injected (Fig. 2). After the semen was injected, the posture of the bitch was maintained for $10 \mathrm{~min}$ to prevent semen reflux. The necessary time for the procedure was considered to be the time to insert the washing tube into the external os of the uterus after inserting the endoscope into the tracheal tube.

The presence of infection was confirmed by clinical symptoms for 30 days after AI. Fetuses and the gestational sac were confirmed by ultrasonography (Sonosite180, SonoSite Inc., Seattle, WA, U.S.A.) at 30 days after AI, and the number of fetuses was confirmed [3, 10, 23]. All data were expressed in means $\pm \mathrm{SD}$.

\section{RESULTS}

Progressive motility of thawed sperm was $58.8 \pm 9.2 \%$, and the sperm malformation rate was $8.6 \pm 2.4 \%$. The serum $\mathrm{P}_{4}$ concentration was $3.7 \pm 0.9 \mathrm{ng} / \mathrm{ml}$ on the LH surge day and $31.3 \pm 10.2 \mathrm{ng} / \mathrm{m} l$ on the day of TCI (Table 1). Ovulation was assumed to have occurred when serum $\mathrm{P}_{4}$ concentration was $>5 n \mathrm{~g} / \mathrm{ml}$, and the AI day was confirmed [1, 2, 4, 14]. Serum $\mathrm{P}_{4}$ concentrations on the day of TCI in this study were $>15 \mathrm{ng} / \mathrm{m} l$.

The TCI procedural time was $7.5 \pm 4.6 \mathrm{~min}$. The bronchial lavage washing tube was inserted approximately $1 \mathrm{~cm}$ into the external os of the uterus within $15 \mathrm{~min}$ in all bitches (Table 1). The tracheal tube was useful as a guide tube for inserting the endoscope into the vagina to ensure a visual field using the air inflated cuff. The amount of cuff air volume in the tracheal tube was $36.7 \pm 5.6 \mathrm{~m} l$ (Table 1). Slight or mild pain was observed in all bitches during AI. However, AI was easily performed without any sedation anesthesia.

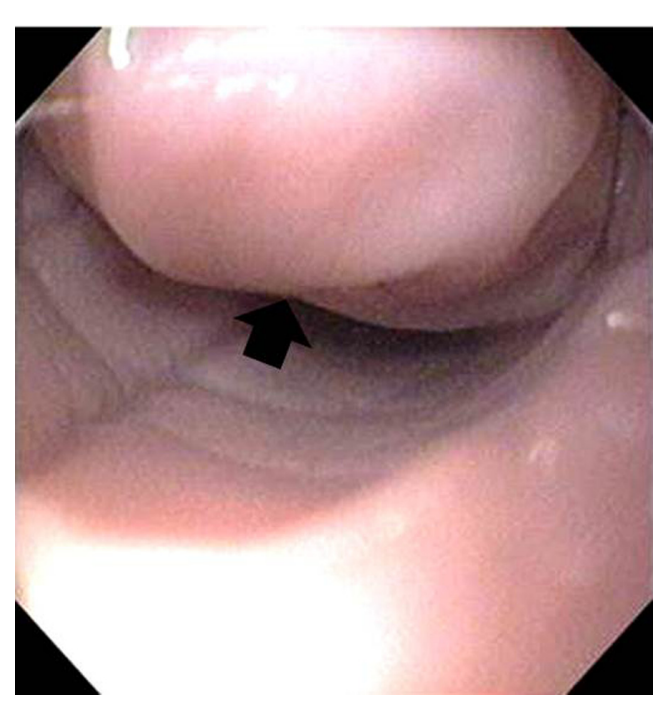

Fig.1. Findings of the external os of the uterus using a flexible endoscope. Arrowhead shows the external os of the uterus.

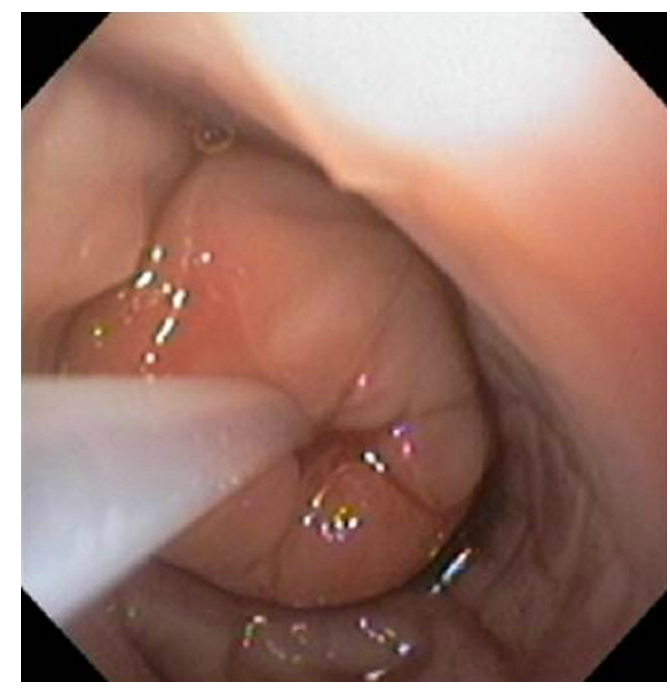

Fig.2. Findings of the washing tube that was inserted into the external os of the uterus from the flexible endoscope channel. 
Table 1. Summary of results in intrauterine TCI using flexible endoscopy

\begin{tabular}{ccccccccccc}
\hline Bitches & $\begin{array}{c}\text { Age } \\
\text { (year) }\end{array}$ & $\begin{array}{c}\text { BW } \\
(\mathrm{kg})\end{array}$ & Parity & $\begin{array}{c}\text { Sperm pro- } \\
\text { gressive } \\
\text { motility (\%) }\end{array}$ & $\begin{array}{c}\text { Sperm mal- } \\
\text { formation } \\
\text { rate }(\%)\end{array}$ & $\begin{array}{c}\text { L } \text { concentrations }(\mathrm{ng} / \mathrm{m} l) \\
\text { day }\end{array}$ & $\begin{array}{c}\text { Cuff } \\
\text { volume } \\
(\mathrm{m} l)\end{array}$ & $\begin{array}{c}\text { Procedure } \\
\text { time }(\mathrm{min})\end{array}$ & $\begin{array}{c}\text { Number of } \\
\text { fetuses }\end{array}$ \\
\hline Bitch 1 & 1 & 13.2 & nulliparous & 65 & 5 & 5.0 & 32.4 & 45 & 12 & 9 \\
Bitch 2 & 6 & 13.0 & parous & 45 & 12 & 2.4 & 24.0 & 45 & 5 & 5 \\
Bitch 3 & 5 & 12.0 & parous & 50 & 9 & 3.9 & 43.1 & 40 & 2 & 5 \\
Bitch 4 & 2 & 15.1 & nulliparous & 70 & 8 & 2.9 & 15.4 & 30 & 8 & 5 \\
Bitch 5 & 6 & 13.6 & parous & 60 & 8 & 3.2 & 26.7 & 35 & 3 & Nonconception \\
Bitch 6 & 2 & 10.7 & nulliparous & 70 & 6 & 3.2 & 24.0 & 35 & 15 & 9 \\
Bitch 7 & 8 & 12.5 & parous & 55 & 11 & 4.6 & 39.0 & 30 & 10 & 6 \\
Bitch 8 & 3 & 12.4 & nulliparous & 55 & 10 & 4.4 & 45.4 & 35 & 5 & 11 \\
\hline Mean \pm SD & $4.1 \pm 2.5$ & $12.8 \pm 1.3$ & N/A & $58.8 \pm 9.2$ & $8.6 \pm 2.4$ & $3.7 \pm 0.9$ & $31.3 \pm 10.2$ & $36.9 \pm 5.9$ & $7.5 \pm 4.6$ & $6.3 \pm 3.4$ \\
\hline
\end{tabular}

TCI: Transcervical insemination, BW: Body weight, $\mathrm{P}_{4}$ : Progesterone, LH: luteinizing hormone, N/A: not applicable, SD: standard deviation

No clinical signs suspicious of infection were observed in any bitch during the pregnancy diagnosis. Seven bitches became pregnant, and the conception rate was $87.5 \%$. The number of fetuses was $6.3 \pm 3.4$ (Table 1). Because non-conception occurred in one bitch, a statistical analysis was not performed. However, no characteristic differences in age, presence of parity, serum $\mathrm{P}_{4}$ concentrations on the days of LH surge and TCI, or sperm quality were observed between the bitches that conceived and those that did not conceive.

\section{DISCUSSION}

The collection of sperm and the preparation of frozen semen were performed as reported previously [11, 16-18, 20]. Sperm motility was $50 \%-70 \%$ in previous studies, which was similar to the rates we obtained, and no abnormalities were observed in sperm malformation rate [9, 27]. In addition, the conception rate was $87.5 \%$ in this study. Thus, the methods for preparing the frozen semen in this study were sufficient for TCI.

The $\mathrm{P}_{4}$ assay method we used has been previously used to estimate the LH surge day $[1,2,4,7,8,14]$. Since the measurement methods for chemiluminescence immunoassay, radioimmunoassay and enzyme immunoassay were almost perfectly correlated, the reference value of the $\mathrm{P}_{4}$ assay method in this study was fixed [2, 4, 14]. Subsequently, the LH surge and TCI days were also estimated by measuring serum $\mathrm{P}_{4}$ concentrations. As a result, the conception rate was $87.5 \%$. Conception rates were $70-90 \%$ in a previous report; thus, TCI timing using this method was appropriate $[9,12]$.

Our study is the first report of TCI performed using a flexible endoscope in dogs. Among the many TCI reports, the method using a rigid endoscope is relatively easy and non-invasive [13]. However, flexible endoscopes are widely used in the field of gastroenterology, and are less invasive than a rigid cystoscope because they are soft [21, 22, 29]. In this study, slight pain was observed, but TCI could be easily performed without anesthesia in all bitches. In addition, procedural time was approximately $8 \mathrm{~min}$, which was shorter than a previous report using a rigid endoscope [13]. This result was considered, because of a good view obtained by air insufflation and higher operability by using an instrument channel as well as increased mobility of the endoscope tip. Therefore, the flexible endoscopy method was considered to be useful for TCI in dogs. However, it is necessary to verify this method on smaller and larger dogs, because we targeted medium-sized dogs with a body weight of about $10 \mathrm{~kg}$.

We used a tracheal tube as a guide tube for the endoscope and as an alternative to the penis [15]. An Osiris catheter has been used as an alternative to the penis [15]; however, these catheters cannot be used as a guide tube for inserting an endoscope. The tracheal tube was useful for inserting the endoscope and securing the field of view. We observed no signs of infection after TCI, suggesting that a tracheal tube is useful as an auxiliary TCI tool with a flexible endoscope.

The conception rate was $87.5 \%$, with six fetuses in this study. The conception rate in a TCI study that used a rigid endoscope was $90 \%$ with 5 fetuses [13]. In addition, the conception rate and number of fetuses are about the same for intravaginal AI with fresh semen $[6,15]$. However, TCI is recommended, because the survival time of sperm is short in frozen semen $[6,25]$. As frozen semen was used in this study and both conception rate and the number of fetuses were similar to previous reports using a rigid endoscope, our method appears more useful for TCI with frozen semen. In the other hand, since one dog that was not pregnant in this study showed no difference in age, presence of parous, serum $\mathrm{P}_{4}$ concentrations and sperm quality, the cause for nonconception was unclear.

This study had one major limitation. This study results were confirmed using ultrasonography of fetuses and the gestational sac, but not confirmed grossly the number of puppies. Therefore, it was unclear whether this method results in a normal gestation period and normal delivery. In addition, since the number of fetuses was confirmed by ultrasonography, it may not be as accurate as those observed in the delivery. Therefore, it is necessary to examine the gestation period, delivery, and the number of fetuses by delivery in the future.

In summary, TCI using a flexible endoscope in dogs was performed quickly with minimal invasiveness. The tracheal tube was useful for inserting the endoscope and to prevent 
infection. In addition, the conception rate and the number of fetuses were similar to previous reports. This method should be studied in small and large breeds to obtain additional detailed results and verify the methodology.

ACKNOWLEDGMENT. We would like to thank Dr. Tetsu Kawamata for his technical inputs in this study.

\section{REFERENCES}

1. Arbeiter, K., Dobretsberger, M., Muller, E. and Holzmann, A. 1991. Indirect detection of ovulation and fertilization in the dog by progesterone level testing. Zentralbl. Veterinarmed. A $\mathbf{3 8}$ : 696-701. [Medline]

2. Chapwanya, A., Clegg, T., Stanley, P. and Vaughan, L. 2008. Comparison of the Immulite and RIA assay methods for measuring peripheral blood progesterone levels in Greyhound bitches. Theriogenology 70: 795-799. [Medline] [CrossRef]

3. Conley, A. J. 1984. Ultrasonographic diagnosis of pregnancy in the dog. Am. J. Vet. Res. 45: 1889. [Medline]

4. de Gier, J., Kooistra, H. S., Djajadiningrat-Laanen, S. C., Dieleman, S. J. and Okkens, A. C. 2006. Temporal relations between plasma concentrations of luteinizing hormone, follicle-stimulating hormone, estradiol-17beta, progesterone, prolactin, and alpha-melanocyte-stimulating hormone during the follicular, ovulatory, and early luteal phase in the bitch. Theriogenology 65: 1346-1359. [Medline] [CrossRef]

5. England, G. C. 1993. Cryopreservation of dog semen: a review. J. Reprod. Fertil. Suppl. 47: 243-255. [Medline]

6. Fontbonne, A. and Badinand, F. 1993. Canine artificial insemination with frozen semen: comparison of intravaginal and intrauterine deposition of semen. J. Reprod. Fertil. Suppl. 47: 325-327. [Medline]

7. Fukushima, F. B., Malm, C., Henry, M., Gheller, V. A., Serakides, R., Neves, M. M., Macedo, S. P., Figueiredo, M. S., Andrade, M. E., Chaves, M. S., Silva, M. X., Rezende, C. M. and Melo, E. G. 2010. Site of intrauterine artificial insemination in the bitch does not affect sperm distribution within the uterus. Reprod. Domest. Anim. 45: 1059-1064. [Medline] [CrossRef]

8. Hase, M., Hori, T., Kawakami, E. and Tsutsui, T. 2000. Plasma LH and progesterone levels before and after ovulation and observation of ovarian follicles by ultrasonographic diagnosis system in dogs. J. Vet. Med. Sci. 62: 243-248. [Medline] [CrossRef]

9. Hori, T., Hagiuda, K., Kawakami, E. and Tsutsui, T. 2005. Unilateral intrauterine insemination with prostatic fluid-sensitized frozen caudal epididymal sperm in beagle dogs. Theriogenology 63: 1573-1583. [Medline] [CrossRef]

10. Jackson, P. G. and Nicholson, J. M. 1979. The use of ultrasound to monitor fetal life in a pregnant bitch. Vet. Rec. 104: 36. [Medline] [CrossRef]

11. Kutzler, M. A. 2005. Semen collection in the dog. Theriogenology 64: 747-754. [Medline] [CrossRef]

12. Linde-Forsberg, C., Ström Holst, B. and Govette, G. 1999. Comparison of fertility data from vaginal vs intrauterine insemination of frozen-thawed dog semen: a retrospective study. Theriogenology 52: 11-23. [Medline] [CrossRef]

13. Macedo, S. P., Malm, C., Henry, M. R., Telles, L. F., Figueiredo, M. S., Fukushima, F. B., Neves, M. M., de Oliveira Cavalcanti, G. A., Chaves, M. S., Mascarenhas, R. M., de Albuquerque Lagares, M. and Gheller, V. A. 2012. Endoscopic transcervical intrauterine artificial insemination in Labrador Retriever bitches. Res. Vet. Sci. 92: 494-500. [Medline] [CrossRef]

14. Moxon, R., Copley, D. and England, G. C. 2010. Technical and financial evaluation of assays for progesterone in canine practice in the UK. Vet. Rec. 167: 528-531. [Medline] [CrossRef]

15. Nizański, W. 2006. Intravaginal insemination of bitches with fresh and frozen-thawed semen with addition of prostatic fluid: use of an infusion pipette and the Osiris catheter. Theriogenology 66: 470-483. [Medline] [CrossRef]

16. Nöthling, J. O., Dolieslager, S. M., Fillekes, R. and Colenbrander, B. 2007. Thawing dog spermatozoa in just-boiled water: submersion time and effect on sperm quality compared to thawing in water at 70 degrees C. Theriogenology 68: 530-537. [Medline] [CrossRef]

17. Peña, A., Johannisson, A. and Linde-Forsberg, C. 1999. Postthaw evaluation of dog spermatozoa using new triple fluorescent staining and flow cytometry. Theriogenology 52: 965-980. [Medline] [CrossRef]

18. Peña, A. and Linde-Forsberg, C. B. 2000. Effects of spermatozoal concentration and post-thaw dilution rate on survival after thawing of dog spermatozoa. Theriogenology 54: 703-718. [Medline] [CrossRef]

19. Rota, A., Ström, B., Linde-Forsberg, C. and RodriguezMartinez, H. 1997. Effects of Equex STM paste on viability of frozen-thawed dog spermatozoa during invitro incubation at 38C. Theriogenology 47: 1093-1101. [Medline] [CrossRef]

20. Rota, A., Ström, B. and Linde-Forsberg, C. 1995. Effects of seminal plasma and three extenders on canine semen stored at 4 degrees C. Theriogenology 44: 885-900. [Medline] [CrossRef]

21. Stasi, K. and Melendez, L. 2001. Care and cleaning of the endoscope. Vet. Clin. North Am. Small Anim. Pract. 31: 589-603. [Medline]

22. Sum, S. and Ward, C. R. 2009. Flexible endoscopy in small animals. Vet. Clin. North Am. Small Anim. Pract. 39: 881-902. [Medline] [CrossRef]

23. Taverne, M. A., Okkens, A. C. and van Oord, R. 1985. Pregnancy diagnosis in the dog: a comparison between abdominal palpation and linear-array real-time echography. Vet. Q. 7: 249-255. [Medline] [CrossRef]

24. Thomassen, R. and Farstad, W. 2009. Artificial insemination in canids: a useful tool in breeding and conservation. Theriogenology 71: 190-199. [Medline] [CrossRef]

25. Thomassen, R., Sanson, G., Krogenaes, A., Fougner, J. A., Berg, K. A. and Farstad, W. 2006. Artificial insemination with frozen semen in dogs: a retrospective study of 10 years using a nonsurgical approach. Theriogenology 66: 1645-1650. [Medline] [CrossRef]

26. Tsutsui, T., Hase, M., Hori, T., Ito, T. and Kawakami, E. 2000. Effects of orvus ES paste on canine spermatozoal longevity after freezing and thawing. J. Vet. Med. Sci. 62: 533-535. [Medline] [CrossRef]

27. Tsutsui, T., Hase, M., Tanaka, A., Fujimura, N., Hori, T. and Kawakami, E. 2000. Intrauterine and intravaginal insemination with frozen canine semen using an extender consisting of orvus ES paste-supplemented egg yolk tris-fructose citrate. J. Vet. Med. Sci. 62: 603-606. [Medline] [CrossRef]

28. Tsutsui, T., Hase, M., Hori, T., Komoriya, K., Shimizu, N., Nagakubo, K. and Kawakami, E. 2000. Effect of addition of Orvus ES paste to frozen canine semen extender on sperm acrosomes. J. Vet. Med. Sci. 62: 537-538. [Medline] [CrossRef]

29. Van Lue, S. J. and Van Lue, A. P. 2009. Equipment and instrumentation in veterinary endoscopy. Vet. Clin. North Am. Small Anim. Pract. 39: 817-837. [Medline] [CrossRef]

30. Wilson, M. S. 1993. Non-surgical intrauterine artificial insemination in bitches using frozen semen. J. Reprod. Fertil. Suppl. 47 307-311. [Medline] 